\title{
Bases of Yield and Production Efficiency in Apple Orchard Systems
}

\author{
Terence L. Robinson and Alan N. Lakso \\ Department of Horticultural Sciences, Cornell University New York State Agricultural Experiment \\ Station, Geneva, NY 14456
}

Additional index words. Malus domestics, light interception, trunk cross-sectional area, canopy volume, yield efficiency, conversion efficiency, partitioning

\begin{abstract}
Bases of orchard productivity were evaluated in four 10-year-old apple orchard systems ('Empire' and 'Redchief Delicious' Malus domestics Borkh. on slender spindle/M.9, Y-trellis/M.26, central leader/M.9/MM.111, and central leader/M.7a). Trunk cross-sectional areas (TCA), canopy dimension and volume, and light interception were measured. Canopy dimension and canopy volume were found to be relatively poor estimators of orchard light interception or yield, especially for the restricted canopy of the Y-trellis. TCA was correlated to both percentage of photosynthetically active radiation (PAR) intercepted and yields. Total light interception during the 7th to the 10th years showed the best correlation with yields of the different systems and explained most of the yield variations among systems. Average light interception was highest with the Y-trellis/M.26 system of both cultivars and approached $70 \%$ of available PAR with 'Empire'. The higher light interception of this system was the result of canopy architecture that allowed the tree canopy to grow over the tractor alleys. The central leader/M.7a had the lowest light interception with both cultivars. The efficiency of converting light energy into fruit (conversion efficiency = fruit yield/light intercepted) was significantly higher for the Y-trellis/M.26 system than for the slender spindle/M.9 or central leader/ M.9/MM.111 systems. The central leader/M.7a system bad the lowest conversion efficiency. An index of partitioning was calculated as the kilograms of fruit per square centimeter increase in TCA. The slender spindle/M.9 system had significantly higher partitioning index than the Y-trellis/M.26 or central leader/M.9/MM.111. The central leader/ M.7a system had the lowest partitioning index. The higher conversion efficiency of the Y/M.26 system was not due to increased partitioning to the fruit; however, the basis for the greater efficiency is unknown. The poor conversion efficiency of the central leader/M.7a was mostly due to low partitioning to the fruit. The Y-trellis/M.26 system was found to be the most efficient in both intercepting PAR and converting that energy into fruit.
\end{abstract}

Orchard planting systems trials have the inherent limitation of providing information only for the particular set of spacings, rootstock, and tree forms growing in a given climate as determined at the beginning of the experiment. To extend the ability to make inferences from such long-term experiments requires a more fundamental understanding of the principles involved in orchard system performance.

The first principle is that total dry matter production and, in many cases, crop yield are related to total light interception (Agha and Buckley, 1986; Hunter and Proctor, 1986; Monteith, 1977; Palmer, 1976, 1989; Palmer and Jackson, 1974). This principle holds for essentially all crops (Monteith, 1977). The slope of this relationship is the net carbon uptake efficiency. In orchard systems that have discontinuous canopies, the spacing and canopy characteristics (height, width, shape, and leaf density) control total light interception, dry matter production, and thus potential yield. Consequently, orchard designs, canopy shapes, or incomplete canopy development that limit total light interception will require proportionately higher efficiency of converting light energy into fruit to obtain high yields per unit area. The light interception model of Jackson and Palmer (1980) showed that the same total light interception could be achieved by five systems that varied by as much as 2-fold in height, 5-fold in clear alley width or basal canopy width, 3-fold in canopy volume, 2-fold in canopy surface area, and almost 2-fold in leaf area index. Since none of these factors alone controlled light interception, all must be considered in designing orchard canopies.

Although maximum fruit yields ultimately are limited by light

Received for publication 3 Aug. 1989. The cost of publishing this paper was defrayed in part by the payment of page charges. Under postal regulations, this paper therefore must be hereby marked advertisement solely to indicate this fact. interception, economic fruit yields and quality are a function of efficiency of light use and light distribution within the canopy (Jackson, 1980; Jackson, et al., 1977; Lakso, 1980; Lakso, et al., 1989; Robinson, et al., 1983). Since adequate localized light exposure is required at the fruiting sites within the canopy, tree designs that maximize exposure within the canopy generally have greater efficiency of conversion of light energy to fruit than canopy designs that allow heavy internal shading. Thus, orchard systems should be evaluated both for their total light interception to estimate potential dry matter productivity as well as for the efficiency of converting total light energy intercepted into fruit yield (Palmer, 1988, 1989).

Indicators of productivity have evolved in an attempt to provide a consistent basis for comparison of tree and orchard productivity. The most common of these are kilograms of fruit per square centimeter of trunk cross-sectional area (TCA) and kilograms of fruit per square meter of canopy volume TCA has proven to be a useful basis on which to express yield per tree size. This expression is based on the correlation of TCA to tree weight (Westwood and Roberts, 1970), which relates to potential bearing sites and to leaf area (Holland, 1968) and which, in turn, relates to light interception and photosynthetic production. Canopy volume has also been commonly used; however, it has a much less sound basis in productivity and is difficult to determine objectively. Within the range of natural-form trees with relatively light pruning, the canopy volume will be correlated to tree size and light interception. It is obvious, though, that leaf area density and number of fruiting sites within the volume, especially in restricted canopies, will have great effects on these relationships. Comparing these different bases of productivity should help clarify the differences in system performante.

Our objectives were to: 1) compare several bases of productivity in various orchard design/management systems, 2) esti- 
mate the efficiency of light energy conversion into fruit, and 3) determine if partitioning, as well as light interception, differs among systems.

\section{Materials and Methods}

In 1978 a 1.8-ha field trial was established to compare four orchard management systems using 'Empire' and 'Delicious' as the test cultivars. The four systems were: 1) slender spindle on M.9 rootstock (SS/M.9) at 1957 and 1495 trees/ha for 'Empire' and 'Delicious', respectively; 2) Y-trellis on M.26 rootstock (Y/M.26) at 1283 and 961 trees/ha; 3) central leader on an M.9 interstem and MM.111 understock (CL/9/111) at 961 and 598 trees/ha; and 4) central leader on M.7a rootstock (CL/M.7) at 450 and 348 trees/ha. Spacings and management for each system were given by Robinson et al. (1991). In years 7 through 10 , fruit number, yield, TCA, canopy height, and canopy width were recorded.

Light interception over the entire area allocated per tree was measured at full canopy in September of years 7 through 10 by hemispherical photography. Black and white photograph negatives of the vertical hemisphere were taken at $30 \mathrm{~cm}$ above the orchard floor with an equidistant $180^{\circ}$ lens using Kodak Tri-X pan film (Lakso, 1980). Photographs along two transects $(\mathrm{N}-$ $\mathrm{S}, \mathrm{E}-\mathrm{W})$, along with the four corners of an under-tree grid extending across rows from alley center to alley center and inrow from tree trunk to tree trunk, were taken at $60-\mathrm{cm}$ intervals under four trees of each system. Additionally, in 1987, a complete grid of pictures was taken under four trees to validate the transect data. Pictures were taken on overcast days to eliminate a dark spot on the film negative from direct sunlight. The film records only the location of physical objects visible in the vertical hemisphere. It does not measure the light intensity at the photographed located and therefore is independent of light conditions. The pictures were analyzed for both diffuse and direct photosynthetically active radiation (PAR) by first digitizing the negative image with an image analyzer and then calculating diffuse PAR from weighted sky area and direct PAR from the solar track. The diffuse light values were calculated by computer dividing the circular hemispherical image into nine concentric circles each of $10^{\circ}$ elevation angle. For estimation of the percentage of diffuse PAR at the location photographed, the percentage of sky area was calculated for each circle, weighted with the cosine of the zenith angle, weighted for luminosity from different regions of a standard overcast sky, corrected for the lens distortion, and then summed. The direct light values were calculated by the computer drawing the solar track on the digitized image and calculating for each 15-min increment of the day the percentage of sky area in a $5^{\circ}$ band width along the solar track. The percentages of each time increment were weighted with the cosine of the zenith angle and summed to give an average percentage of sky along the solar track. This figure was defined as the percentage of direct PAR at the location photographed. The diffuse and direct light values were then averaged by using the seasonal ratio of diffuse : direct light for Geneva, N.Y. (typically $42 \%$ diffuse and $58 \%$ direct).

Light interception was calculated from the transect data by fitting a response surface to the data using the SAS G3-grid procedure with a spline curve smoothing option. The area under the response surface curves for each measured tree was integrated to give the percentage of available PAR intercepted by the tree canopy in September of each year. Seasonal PAR flux from 1 May to 1 Oct. was calculated using data from the New York State Agricultural Experiment Station (Geneva) weather station by assuming $50 \%$ of total radiation was PAR and then multiplying PAR by light interception in September to obtain an estimated total PAR intercepted by the trees for the season. The overestimation of light interception by the incomplete canopies in May is approximately compensated by light interception in October.

The experiment was a $2 \times 4$ factorial of cultivar and production system, in a randomized complete-block design with two replications and two subsamples. Data were collected for each subsample row in each whole plot, and guard rows were not included in the analysis. Years were treated as repeated measures. The variance due to whole plots was tested for statistical difference from the variance due to subsamples. When the two variances were not different, they were combined and used as the error term in the analysis of variance to test significance of, treatment effects. The variances due to subsamples and whole plot units were combined for all dependent variables except light interception. Regression analysis was performed with cumulative 4-year yield and PAR intercepted. Analysis of covariance was performed on the residuals to determine the effect of treatment independent of light interception differences.

\section{Results}

Light interception. The percentage of light intercepted was greater for 'Empire' than for 'Delicious' in all years and for the 4-year average (Table 1). Among systems, the Y/M.26 system had the highest average light interception, followed by the SS/ M.9, CL/9/111, and CL/M.7 systems. With 'Empire', the Y/ M.26, SS/M.9, and CL/9/111 trees were at a fairly constant total light interception over the 4 years of $\approx 69 \%, 51 \%$, and $43 \%$, respectively, but the CL/M.7 trees increased from $35 \%$ to $48 \%$ over the 4 years. With 'Delicious', only the Y/M.26 was at a constant level of light interception, at $\approx 45 \%$. There was no significant cultivar $\times$ system interaction in any year.

The percentage of light intercepted each year by each orchard

Table 1. Light interception in September for 'Empire' and 'Delicious' apple trees grown in four orchard management systems.

\begin{tabular}{|c|c|c|c|c|c|c|}
\hline \multirow[b]{3}{*}{ Cultivar } & \multirow[b]{3}{*}{ System } & \multicolumn{5}{|c|}{ PAR intercepted $(\%)$} \\
\hline & & \multicolumn{4}{|c|}{$\begin{array}{c}\text { Tree age (years) and } \\
\text { calendar year }\end{array}$} & \multirow[b]{2}{*}{$\begin{array}{c}\text { 4-year } \\
\text { mean }\end{array}$} \\
\hline & & $\begin{array}{c}7 \\
1984 \\
\end{array}$ & $\begin{array}{c}8 \\
1985 \\
\end{array}$ & $\begin{array}{c}9 \\
1986 \\
\end{array}$ & $\begin{array}{c}10 \\
1987 \\
\end{array}$ & \\
\hline Empire & & 50 & 47 & 54 & 54 & 51 \\
\hline Delicious & & 26 & 28 & 35 & 36 & 31 \\
\hline \multirow[t]{6}{*}{$\mathrm{LSD}_{0.05^{2}}$} & & 6 & 7 & 8 & 7 & 6 \\
\hline & Slender Sp./M.9 & 41 & 39 & 47 & 45 & 43 \\
\hline & Y-trellis/M.26 & 54 & 51 & 61 & 58 & 56 \\
\hline & C.L./M.9/MM.111 & 31 & 30 & 34 & 38 & 33 \\
\hline & C.L./M.7a & 26 & 28 & 36 & 38 & 32 \\
\hline & $\operatorname{LSD}_{0.05^{z}}$ & 9 & 10 & 11 & 10 & 9 \\
\hline \multirow[t]{4}{*}{ Empire } & Slender Sp./M.9 & 53 & 45 & 54 & 51 & 51 \\
\hline & Y-trellis/M.26 & 67 & 65 & 73 & 70 & 69 \\
\hline & C.L./M.9/MM.111 & 45 & 40 & 43 & 45 & 43 \\
\hline & C.L./M.7a & 35 & 37 & 47 & 48 & 42 \\
\hline \multirow[t]{4}{*}{ Delicious } & Slender Sp./M.9 & 29 & 33 & 41 & 38 & 35 \\
\hline & Y-trellis/M.26 & 41 & 38 & 48 & 46 & 43 \\
\hline & C.L./M.9/MM.111 & 18 & 21 & 25 & 31 & 23 \\
\hline & C.L./M.7a & 17 & 19 & 26 & 29 & 23 \\
\hline
\end{tabular}

$\operatorname{LSD}_{0.05}{ }^{2}$

${ }^{2}$ Wherever main effect LSD values are not presented, the cultivar $x$ system interaction was significant at $P=0.05 . \mathrm{n}=16$ for cultivar means; $\mathrm{n}=8$ for system means; $\mathrm{n}=4$ for cultivar $\times$ system means. 
Table 2. Regressions between various tree measurements (x) and percentage of light intercepted/ha (y) for 'Empire' and 'Redchief Delicious' apple trees under four management systems over 4 years (1984-1987).

\begin{tabular}{|c|c|c|c|c|c|}
\hline \multirow[b]{2}{*}{ Tree measurements $(\mathbf{x})$} & \multicolumn{5}{|c|}{ Regression equations for estimating percent light interception (y) } \\
\hline & Type of curve & $r^{2}$ & Intercept & Slope of $\mathrm{x}$ & Slope of $x^{2}$ \\
\hline \multicolumn{6}{|c|}{ Regressions using all four orchard management systems } \\
\hline $\mathrm{TCA}^{2} / \mathrm{ha}\left(\mathrm{m}^{2}\right)$ & Quadratic** & 0.81 & +6.8 & +13.4 & -0.6 \\
\hline Canopy vol./ha $\left(1000 \mathrm{~m}^{3}\right)$ & Quadratic* & 0.45 & +12.9 & +9.7 & -0.5 \\
\hline Tree ht : clear alley ratio & Quadratic** & 0.28 & -5.9 & +74.7 & -24.3 \\
\hline Trec ht : row spacing ratio & Linear** & 0.61 & -25.9 & +121.0 &.-- \\
\hline \multicolumn{6}{|c|}{ Regressions without Y-trellis/M.26 system } \\
\hline $\mathrm{TCA} / \mathrm{ha}\left(\mathrm{m}^{2}\right)$ & Quadratic** & 0.75 & +3.0 & +16.7 & -1.3 \\
\hline Canopy vol./ha $\left(1000 \mathrm{~m}^{3}\right)$ & Quadratic** & 0.60 & +10.5 & +9.0 & -0.5 \\
\hline Tree ht : clear alley ratio & Quadratic** & 0.72 & -13.1 & +69.1 & -18.9 \\
\hline Tree ht : row spacing ratio & Linear** & 0.62 & -21.5 & +106.0 & -- \\
\hline
\end{tabular}

${ }^{2} \mathrm{TCA}=$ trunk cross-sectional area.

*,** Significant at $P=0.05$ or 0.01 , respectively. $\mathrm{n}=32$ with four systems and $\mathrm{n}=24$ with three systems.

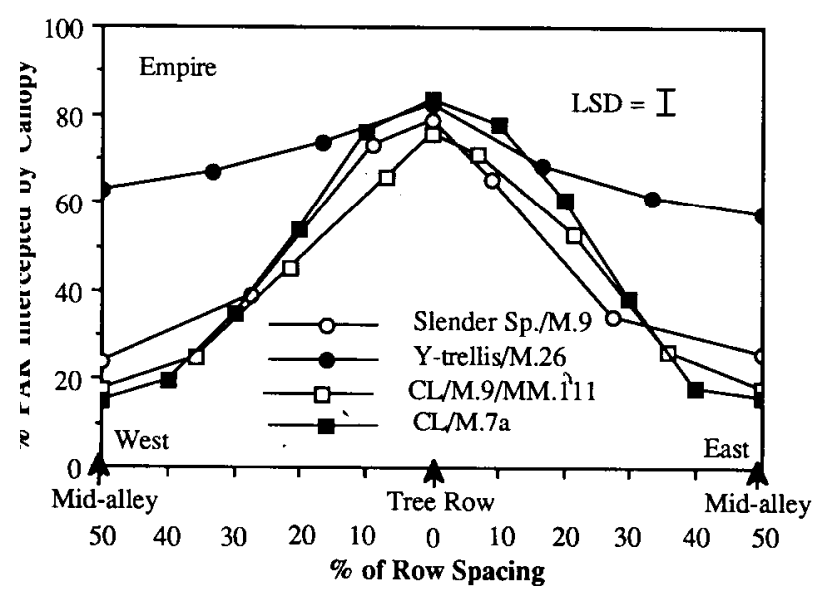

Fig. 1. Light interception across the row for 'Empire' apple trees grown under four orchard systems in 1987 (row spacing converted to a percentage for each system with the tree trunk at $0 \%$ ). Vertical bar represents LSD, $5 \%, \mathrm{n}=4$.

system was correlated with various tree measurements. TCA/ ha, canopy volume/ha, tree height : clear alley width ratio, and tree height : row spacing ratio were all correlated with total light interception/ha (Table 2). The best correlation for all 4 years was with TCA/ha $\left(r^{2}=0.81\right)$. This relationship was better in the early years $\left(r^{2}=0.91\right.$ in 1984) and poorer in the later years $\left(r^{2}=0.81\right.$ in 1987). The relationship was poorer with the canopy volume and tree height : clear alley width ratio methods. The Y/M.26 system did not fit the same relationship as that of the other systems; when it was excluded from the relationship, the correlation improved significantly with these two methods (Table 2).

Comparisons of light interception across the row in 1987 for each of the four 'Empire' systems showed that light interception directly in the tree row was high for all systems and ranged from $70 \%$ to $80 \%$. With the SS/M.9, CL/9/111, and CL/M.7 systems, light interception declined rapidly out in the tractor alley to only $15 \%$ for the widely spaced CL/M.7 trees and to $25 \%$ for the closely spaced SS/M.9 (Fig. 1). With the Y/M.26 system, light interception directly under the tree was similar to the other systems, but the levels of interception remained between $50 \%$ to $60 \%$ in the alleyways.

Cumulative intercepted PAR was highly correlated $\left(r^{2}=0.86\right)$ to cumulative yield over the 4 years of this study (Fig. 2). To

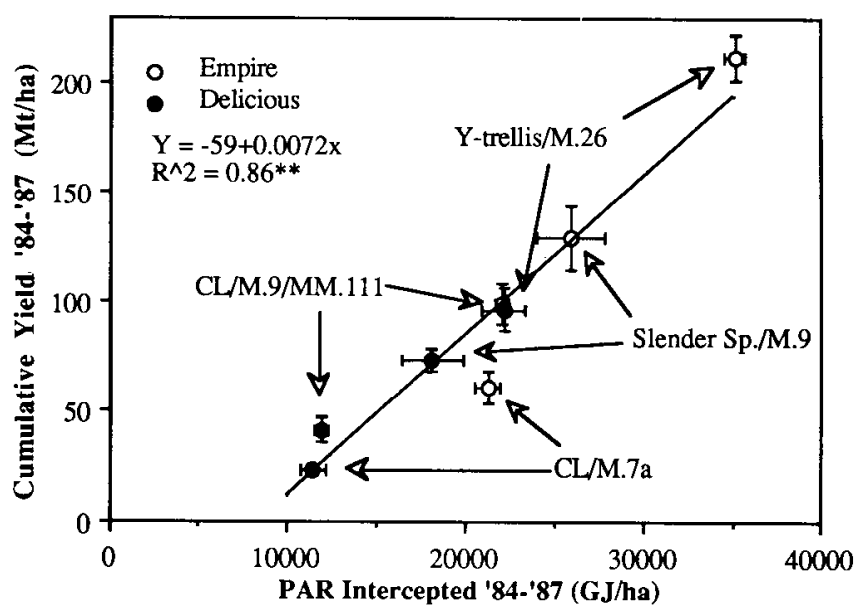

Fig. 2. Correlation of cumulative yield (1984-1987) and PAR intercepted (1984-1987) for 'Empire' and 'Delicious' apple trees grown under four orchard systems (each data point is the average of four observations $\pm \mathrm{SE}$ ).

examine the effects of management system independently of light interception, cumulative yields were adjusted for the effect of light intercepted by analysis of covariance. With both cultivar, the Y/M.26 had the highest unadjusted yield from 19841987, followed by the SS/M.9 trees, the CL/9/111 trees, and lastly the CL/M.7 trees (Table 3). When yields were adjusted for intercepted PAR, the 'Empire' Y/M.26 system had the highest yield, but it was no longer significantly different from the SS/M.9 and the CL/9/111 systems. Only the CL/M.7 system had significantly lower adjusted yield. With 'Delicious', there were no significant differences in adjusted yield. In addition, the differences between cultivars disappeared after adjustment for the amount of PAR intercepted.

Conversion efficiency. The efficiency of converting light energy into fruit was defined as yield per unit of PAR intercepted and was termed conversion efficiency (Table 4). 'Empire' was more efficient than 'Delicious' in 1984 and 1987 but there were no significant differences due to cultivar in the other 2 years. In 1984 and 1987, there were significant interactions of cultivar and system. With 'Empire' in 1984 and 1985 there were no differences among the SS/M.9, Y/M.26, or CL/9/111 systems in conversion efficiency. However, in the last 2 years the $\mathrm{Y} /$ M.26 system had significantly higher efficiency than the other two systems. Over the 4 years studied, the Y/M.26 system had 
Table 3. Cumulative PAR intercepted and yield (1984-1987) of 'Empire' and 'Delicious' apple trees grown in four orchard production systems.

\begin{tabular}{|c|c|c|c|c|}
\hline \multirow[b]{2}{*}{ Cultivar } & \multirow[b]{2}{*}{ System } & \multirow{2}{*}{$\begin{array}{c}\text { Cumulative } \\
\text { PAR intercepted } \\
\text { (GJ } \cdot \mathrm{ha}^{-1} \text { ) } \\
\text { 1984-1987 }\end{array}$} & \multicolumn{2}{|c|}{ Cumulative yield $\left(\mathrm{t} \cdot \mathrm{ha}^{-1}\right)$} \\
\hline & & & $\begin{array}{l}\text { Unadjusted } \\
1984-1987\end{array}$ & $\begin{array}{r}\text { Adjusted } \\
\text { for PAR } \\
1984-1987\end{array}$ \\
\hline Empire & & 26,100 & 126 & 89 \\
\hline Delicious & & 16,200 & 59 & 95 \\
\hline \multirow[t]{4}{*}{$\operatorname{LSD}_{0.05^{y}}$} & & 2,800 & & \\
\hline & Slender Sp./M.9 & 22,000 & 102 & 94 \\
\hline & Y-trellis/M.26 & 28,600 & 155 & 100 \\
\hline & C.L./M.9/MM.111 & 17,000 & 71 & 92 \\
\hline \multirow[t]{2}{*}{$\therefore$} & C.L./M.7a & 13,900 & 43 & 75 \\
\hline & $\operatorname{LSD}_{0.05^{y}}$ & 3,960 & & \\
\hline \multirow[t]{4}{*}{ Empire } & Slender Sp./M.9 & 25,900 & 130 & 94 \\
\hline & Y-trellis/M.26 & 35,200 & 212 & 110 \\
\hline & C.L./M.9/MM.111 & 22,000 & 100 & 92 \\
\hline & C.L./M.7a & 21,300 & 61 & 59 \\
\hline \multirow[t]{4}{*}{ Delicious } & Slender Sp./M.9 & 18,100 & 73 & 94 \\
\hline & Y-trellis/M.26 & 22,100 & 97 & 89 \\
\hline & C.L./M.9/MM.111 & 12,000 & 42 & 106 \\
\hline & C.L./M.7a & 11,600 & 24 & 91 \\
\hline $\operatorname{LSD}_{0.05^{y}}$ & & & 23 & 26 \\
\hline
\end{tabular}

${ }^{2}$ Adjusted yield $=$ grand mean + residual from the regression of PAR $(x)$ and yield (y).

${ }^{y}$ Wherever main effect LSD values are not presented, the cultivar $\times$ system interaction was significant at $P=0.05 . \mathrm{n}=16$ for the cultivar means; $\mathrm{n}=8$ for the system means; $\mathrm{n}=4$ for the cultivar $\times$ system means.

Table 4. Efficiency of converting light energy into fruit (fresh-weight basis) and partitioning index for 'Empire' and 'Delicious' apple trees grown in four orchard management systems (1984-1987).

\begin{tabular}{|c|c|c|c|c|c|c|c|c|c|c|c|}
\hline \multirow[b]{3}{*}{ Cultivar } & \multirow[b]{3}{*}{ System } & \multicolumn{5}{|c|}{$\begin{array}{l}\text { Conversion efficiency } \\
\text { (g fruit/MJ PAR) }\end{array}$} & \multicolumn{5}{|c|}{$\begin{array}{c}\text { Partitioning index } \\
\left(\mathrm{kg} \text { fruit } / \mathrm{cm}^{2}\right. \\
\text { increase in TCA) }\end{array}$} \\
\hline & & \multicolumn{8}{|c|}{ Tree age (years) and calendar year } & \multirow[b]{2}{*}{$\begin{array}{c}3-\mathrm{yr} \\
\text { cum. }\end{array}$} & \multirow[b]{2}{*}{$\begin{array}{l}10-\mathrm{yr} \\
\text { cum. }\end{array}$} \\
\hline & & $\begin{array}{c}7 \\
1984 \\
\end{array}$ & $\begin{array}{c}8 \\
1985 \\
\end{array}$ & $\begin{array}{c}9 \\
1986 \\
\end{array}$ & $\begin{array}{c}10 \\
1987 \\
\end{array}$ & $\begin{array}{l}\text { 4-year } \\
\text { cum. }^{2}\end{array}$ & $\begin{array}{c}8 \\
1985 \\
\end{array}$ & $\begin{array}{c}9 \\
1986\end{array}$ & $\begin{array}{c}10 \\
1987\end{array}$ & & \\
\hline$\overline{\text { Empire }}$ & & 3.4 & 6.9 & 4.0 & 4.4 & 4.6 & 9.5 & 6.1 & 4.4 & 6.1 & 3.5 \\
\hline Delicious & $\cdot$ & 2.5 & 6.3 & 3.3 & 2.4 & 3.5 & 8.5 & 5.0 & 5.8 & 5.7 & 2.8 \\
\hline \multirow[t]{6}{*}{$\operatorname{LSD}_{0.05^{y}}$} & & & 1.0 & 0.8 & & 0.6 & 1.7 & 2.5 & 2.5 & & 0.3 \\
\hline & Slender Sp./M.9 & 4.1 & 7.4 & 3.8 & 3.3 & 4.6 & 12.9 & 7.7 & 4.6 & 7.7 & 3.9 \\
\hline & Y-trellis/M.26 & 3.4 & 7.2 & 5.1 & 5.4 & 5.2 & 8.7 & 7.2 & 7.5 & 7.1 & 3.5 \\
\hline & C.L./M.9/MM.111 & 3.0 & 6.8 & 3.6 & 3.0 & 4.0 & 9.1 & 4.8 & 6.6 & 5.9 & 3.0 \\
\hline & C.L./M.7 & 1.1 & 5.1 & 2.1 & 1.8 & 2.5 & 5.3 & 2.7 & 1.8 & 3.0 & 1.9 \\
\hline & $\operatorname{LSD}_{0.05^{y}}$ & & 1.5 & 1.1 & & 0.8 & 2.4 & 3.5 & 3.5 & & 0.4 \\
\hline \multirow[t]{4}{*}{ Empire } & Slender Sp.M.9 & 4.3 & 7.9 & 4.0 & 4.0 & 5.0 & 14.3 & 10.4 & 5.9 & 9.3 & 4.6 \\
\hline & Y-trellis/M.26 & 4.5 & 7.1 & 5.5 & 7.1 & 6.0 & 8.2 & 6.1 & 5.1 & 6.1 & 3.7 \\
\hline & C.L./M.9/MM.111 & 3.5 & 7.2 & 4.0 & 3.6 & 4.5 & 10.0 & 4.5 & 4.2 & $\begin{array}{l}0.1 \\
5.7\end{array}$ & 3.2 \\
\hline & C.L./M.7 & 1.1 & 5.3 & 2.3 & 2.8 & 2.9 & 5.3 & 3.4 & 2.4 & 3.4 & 2.3 \\
\hline \multirow[t]{4}{*}{ Delicious } & Slender Sp./M.9 & 3.9 & 6.8 & 3.5 & 2.5 & 4.1 & 11.5 & 4.9 & 3.2 & 6.0 & 3.3 \\
\hline & Y-trellis/M.26 & 2.3 & 7.2 & 4.7 & 3.7 & 4.4 & 9.1 & 8.2 & 9.8 & 8.0 & 3.4 \\
\hline & C.L./M.9/MM.111 & 2.5 & 6.3 & 3.1 & 2.4 & 3.5 & 8.1 & 5.0 & 8.9 & 6.0 & 2.8 \\
\hline & C.L./M. 7 & 1.1 & 4.8 & 1.9 & 0.8 & 2.0 & 5.3 & 2.0 & 1.1 & 2.6 & 1.6 \\
\hline $\operatorname{LSD}_{0,05}{ }^{y}$ & & 1.1 & & & 0.9 & & & & & 2.3 & \\
\hline
\end{tabular}

${ }^{2}$ Cumulative conversion efficiency calculated using 4-year cumulative yield and intercepted PAR (1984-1987). Three-year cumulative partitioning index calculated using 3-year cumulative yield and 3-year increase in TCA. Ten-year cumulative partitioning index calculated from 10-year cumulative yield and 10-year increase in TCA. ${ }^{\gamma}$ Wherever main effect LSD values are not presented, the cultivar $\times$ system interaction was significant at $P=$ 0.05 . $n=16$ for the cultivar means; $n=8$ for the system means; $n=4$ for the cultivar $\times$ system means.

the highest cumulative efficiency followed by the SS/M.9 and CL/9/111. With 'Delicious', the SS/M.9 system had the highest efficiency in 1984 but Y/M.26 had the highest in the remaining 3 years. There were no significant differences in cumulative conversion efficiency among the SS/M.9, Y/M.26, and CL/9/ 111 systems. The CL/M.7 always had the lowest efficiency with both cultivars.

To estimate partitioning between fruit and vegetative growth, 
an index was defined as the ratio of fruit yield to increment increase in TCA. In the 3 years where this index was calculated, there was no effect due to cultivar in any year or in the cumulative index. With 'Empire', the SS/M.9 system always had the highest partitioning index followed by Y/M.26 and CL/9/111. The CL/M.7 system had the lowest partitioning index. With 'Delicious', SS/M.9 had the highest partitioning index in only 1985. In the other 2 years, Y/M.26 had a higher partitioning index, but only in 1987 was the difference significant. The 3year cumulative index showed no difference among the SS/M.9, Y/M.26, and CL/9/111 systems with only the CL/M.7 having a lower index. The calculation of a 10-year partitioning index using 10-year cumulative yield and net increase in TCA showed the same pattern as the 3-year index, but the values for the years 8-10 were. higher than the 10 -year index.

The efficiency of converting light energy into fruit was correlated with the partitioning index $\left(r^{2}=0.54\right.$, conversion efficiency $=1.61+0.42$ žpartitioning index, $\mathrm{n}=8$ ). The 'Empire' Y/M.26 system did not fit the relationship well since it had the highest conversion efficiency but not the highest partitioning index. Excluding the 'Empire' Y/M.26 system from the correlation gave $r^{2}=0.84$ (conversion efficiency $=1.41+0.41 \bullet$ partitioning index, $\mathrm{n}=7$ ).

A multiple regression model over both cultivars and all systems using the 4-year average yield as the dependent variable and PAR intercepted, conversion efficiency, and partitioning index as the independent variables, accounted for $97 \%$ of the variation in yield (Table 5). PAR intercepted accounted for $86 \%$ of the variation and conversion efficiency 'accounted for $11 \%$. Partitioning index did not 'account for a significant portion of the variation.

\section{Discussion}

The lower light interception of 'Delicious' compared to 'Empire' was the result of wider planting distances and reduced growth with the 'Redchief Campbell' strain of 'Delicious' (Robinson et al., 1991). In all systems with 'Delicious', the trees had not filled their allotted space by the end of the 10th year and light interception was still relatively low. Among systems, the greater light interception by the Y/M.26 system resulted from the geometric shape of the Y-hedgerow. The Y/M.26 system allowed less light to fall on the alleys between rows as a result of the arms of the Y-trellis growing over the tractor alleyways (Fig. 1). With the other three systems, which are all vertically stacked, pyramid-shaped trees, light interception dropped in the alley to only $15 \%$ for the widely spaced CL/M.7 trees and to $25 \%$ for the closely spaced SS/M.9. With the pyramid-shaped trees, considerable light is lost by having tractor alleys between rows. Even at maturity, the SS/M.9 trees only intercepted $\approx 50 \%$ of available light. It follows that one way to achieve the light interception of the Y/M.26 system with pyramid-shaped trees would be to use multiple row systems where the number of tractor alleys can be reduced (Jackson et al., 1987; Palmer, 1988; Wertheim et al., 1986). Palmer (1988) has reported that with a full field system with 'Crispin' apples, light interception was in the $70 \%$ to $80 \%$ range. Although high levels of light interception can be achieved with full field systems, the elimination of the tractor alleys makes management more difficult, and the need for a very high number of trees increases the expense for orchard establishment. It is significant that the Y/M.26 can achieve similar levels of light interception at a moderate tree density while still maintaining the tractor alleyways for ease of management and harvest.

The correlation of fruit yield with PAR intercepted accounts for a major portion of the variation in yield attributed to management system. This result indicates that the major difference among the orchard systems compared in this study was light interception (Jackson, 1978; Palmer, 1986). After adjustment for PAR intercepted, only the 'Empire' CL/M.7 system had significantly lower adjusted yield compared to all the other combinations. This result is likely due to poorer light distribution within the canopy and to growth and cropping characteristics of the rootstock. It is significant that there were no differences due to cultivar after adjustment for PAR intercepted. 'Delicious' has the reputation of cropping poorly in New York. These data indicate much of the problem likely is that 'Delicious' orchards intercept too little light due to reduced growth and wider than optimum planting distances (Ferree et al., 1989).

Because of the high correlation of light interception and yield, a method to estimate light interception in various orchards would help apple growers understand the performance of their orchards. In our study, light interception was highly correlated to TCA/ha and the relationship was the same for all systems. Although it would be simple to estimate TCA/ha, the relationship of TCA/ha to light interception will likely change as an orchard matures. TCA/ha continues to increase but light interception levels off once the trees fill their allotted space. Palmer (1987) showed that leaf area/tree also levels off with maturity while TCA continues to increase. The 'Empire' SS/M.9 and the Y/ M.26 systems in our study were at a constant light interception over the last 3 years of the study, but total TCA/ha continued to increase, which resulted in a lower $r^{2}$ for the relationship in the later years compared to 1984. This problem limits the value of TCA/ha as a method of estimating light interception in a wide variety of orchards, especially after allotted space is filled. However, in the early years, this simple measure should be a useful method of estimating light interception. Robinson et al. (1991) have shown that TCA/ha is highly correlated to cumu-

Table 5. Multiple regression model of average yield per hectare $(\mathrm{y})$ and PAR intercepted/ha $\left(\mathrm{x}_{1}\right)$, conversion efficiency $\left(\mathrm{X}_{2}\right)$, and partitioning index $\left(\mathrm{x}_{3}\right)$ for 'Empire' and 'Redchief Delicious' apple trees under four management systems over 4 years (1984-1987).

\begin{tabular}{lrcc}
\hline Sources of variation & df & $\begin{array}{c}\text { Sum of } \\
\text { squares }\end{array}$ & $\begin{array}{c}\text { Slope } \\
\text { estimate }\end{array}$ \\
\hline Mean annual PAR intercepted $\left(\mathrm{GJ} \cdot \mathrm{ha}^{-1}\right)$ & 1 & $90,000^{* *}$ & +0.00047 \\
Mean annual conversion efficiency $(\mathrm{kg} \mathrm{fruit} / \mathrm{GJ}$ PAR intercepted) & 1 & $11,700^{* *}$ & +4.9 \\
Mean annual partitioning index $\left(\mathrm{kg}\right.$ fruit/ $\mathrm{cm}^{2}$ increase in TCA) & 1 & $300^{\mathrm{NS}}$ & -0.0004 \\
Error & 28 & 3,100 & \\
Total & 31 & 105,100 & \\
Intercept $\left(\mathrm{t} \cdot \mathrm{ha}^{-1}\right)$ & & & -21 \\
\hline
\end{tabular}

Ns, ${ }^{* *}$ Nonsignificant or significant at $P=0.01$, respectively. 
lative yield in the first 10 years of an orchard's life $\left(r^{2}=0.87\right.$, Cum. yield/ha $=-31+0.004 \cdot \mathrm{TCA} / \mathrm{ha})$.

Other tree measurements, such as canopy volume and tree height and clearance, were not as well-correlated to light interception when the Y/M.26 system was included (Table 2). By excluding the Y/M.26 system from the relationship, light interception could be estimated by measuring the ratio of tree height to clear alley, canopy volume, or the ratio of tree height to row spacing, although the $r^{2}$ values ranged from 0.60 to 0.72 . The model of Palmer (1980) showed tree height and row spacing are major factors influencing light interception for pyramid-shaped trees. Our data confirm this point and illustrate that, for pyramid-shaped trees, light interception can be estimated from the height : clear alley width ratio. For restricted systems such as the Y/M.26, estimators based on correlations in natural forms are inadequate. It appears that light interception will need to be estimated directly when comparing systems of varying shapes.

' The efficiency of converting light energy into fruit is an integrative measure of efficiency of the tree system to produce dry matter from intercepted light (assimilation efficiency) and to partition carbon to the fruit (harvest index). In the long term, this measure incorporates the effects of light on return bloom, fruit set, fruit size, and photosynthetic efficiency. Measuring conversion efficiency allows comparisons of the physiological efficiency of systems independently of planting density and light interception differences. In our study, the Y/M.26 system had the highest conversion efficiency and the CL/M.7 system had the lowest efficiency. On this basis, it can be expected that the less-efficient systems would have lower yield than other systems at the same light interception level.

Palmer (1988) measured conversion efficiency on a dry-weight basis with 'Crispin'/M.27 trees grown in a bed system. In our study, fruit dry weight averaged $16 \%$ (range $14 \%$ to $17 \%$ ) for the 4 years, which gives efficiency values on a dry-weight basis ranging from a high average of $0.96 \mathrm{~g}$ for the 'Empire' Y/M.26 to a low of $0.32 \mathrm{~g}$ fruit dry weight/MJ PAR intercepted for the 'Delicious', CL/M.7. Our values are similar, but slightly lower than those calculated from Palmer's data (1988) on the triploid 'Crispin' that show conversion efficiency values of 1.04 to 1.24 $\mathrm{g}$ fruit dry weight/MJ PAR. Palmer (1989) has also shown similar results for 'Golden Delicious'/M.9a with efficiency values of $=0.73$ to 1.05 . These studies are not strictly comparable to ours, because the methods used to estimate seasonal light interception differed. Nonetheless, the efficiency values are of similar magnitude and are comparable among the three studies.

Since TCA is correlated to the above-ground weight of apple trees (Westwood and Roberts, 1970), it follows that the annual increase in TCA is a measure of the annual vegetative growth. Thus, the ratio of yield to the increase in TCA is an estimate of partitioning between fruit and vegetative growth and is similar to harvest index. There were no significant differences due to cultivar in partitioning of dry matter to the fruit, but within cultivars there were differences due to system. With 'Empire', the SS/M.9 had the highest level of partitioning, and the CL/ M.7 the lowest. With 'Delicious' the Y/M.26 had the highest harvest index, and the CL/M.7 the lowest. The partitioning index was highly correlated to the efficiency of converting PAR into fruit, especially when the 'Empire' Y/M.26 system was excluded. This result indicates that the differences in energy conversion efficiency are largely due to partitioning. The exception was the 'Empire' Y/M.26, which had the highest conversion efficiency but had significantly lower partitioning index than the SS/M.9 system. The basis for the high efficiency of the Y/M.26 system is unknown, but could be due to either increased photosynthetic efficiency, thereby resulting in greater carbon availability for both fruit and vegetative growth, or improved flowering and fruit set induced by better light distribution to fruiting spurs.

From this analysis it seems clear that the relatively high yield of the 'Empire' SS/M.9 system was the result of moderately high light interception and a high partitioning of carbon into fruit. The reduced vegetative growth induced by the M.9 root system was likely a poorly competing sink after the tree matured and cropped. With the 'Empire' Y/M.26 system, the high yield was the result of both high light interception and high conversion efficiency. The high conversion efficiency was not the result of greater partitioning, but suggests that both fruit and vegetative growth could be supported. With the CL/M.7 the poor yield was the result, of both low light interception and poor conversion efficiency, largely due to lower partitioning of dry matter into fruit and more partitioning into the more vigorous vegetative growth induced by the more vigorous M.7 rootstock. It is unknown whether the effects on conversion and partitioning index noted here are due only to rootstock or also to training system or spacing. To separate these effects would require the systems to be compared on several rootstock at several spacings.

The purpose of the multiple regression analysis of yield was to develop a statement whereby the relative productive capacity of systems could be estimated by knowing light interception and having an estimate of conversion efficiency and partitioning efficiency. Although, in this analysis, partitioning index did not account for a significant portion of the yield variation, it would be expected that with similar tree shapes it would be significant. The light interception models of Jackson (1981) and Palmer (1981) could be used to obtain estimates of light interception of various orchard systems and partitioning index data could be obtained from uniform rootstock trials. Conversion efficiency estimates could be obtained from the work of Palmer (1988) and the data presented here.

It is clear that the differences in yield between systems and cultivars were largely the result of the differences in light interception. Besides differences in light interception, our data also show that apple orchard management systems can differ in the use of intercepted light energy. The physiological bases of these differences need to be elucidated.

\section{Literature Cited}

Agha, N.S.A. and W.R. Buckley. 1986. Assessment of canopy efficiency of apple trees in beds. L Canopy development assessed by direct light measurements. J. Hort Sci. 61:153-159.

Ferree, D. C., R.C. Funt, and B.L. Bishop. 1989. Yield and production efficiency of four apple cultivars in selected orchard management systems. J. Amer. Soc. Hort. Sci. 114:863-868.

Hunter, D.M. and J.T.A, Proctor. 1986. The correlation of light interception with yield and fruit color of McIntosh apple strains. Fruit Var. J. 40:79-86.

Holland, D.A. 1968. The estimation of total leaf area on a tree. Rpt. E. Mailing Res. Sta. 1967:101-104.

Jackson, J.E. 1978. Utilization of light resources by HDP systems. Acts Hort. 65:61-70.

Jackson, J.E. 1980. Light interception and utilization by orchard systems. Hort. Rev. 2:208-267.

Jackson, J.E. 1981. Theory of light interception by orchards and a modeling approach to optimizing orchard design. Acts Hort. 114:69-79.

Jackson, J.E. and J.W. Palmer. 1980. A computer model study of light interception by orchards in relation to mechanized harvesting and management. Scientia Hort. 13:1-7.

Jackson, J. E., J.W. Palmer, M.A. Perring, and R.O. Sharples. 1977. 
Effects of shade on the growth and cropping of apple trees. III Effects on fruit growth, chemical composition and quality at harvest and after storage. J. Hort. Sci. 52:267-282.

Jackson, J. E., S.J. Wertheim, B. Buenemann, F. Winter, J.V. Christensen, S. Sansavini, and A. Mika. 1987. The international planting systems trial. HortScience 22:550-551.

Lakso, A.N. 1980. Correlations of fisheye photography to" canopy structure, light climate and biological responses to light in apple trees. J. Amer. Soc. Hort. Sci. 105:43-46.

Lakso, A. N., T.L. Robinson, and R.M. Pool. 1989. Canopy microclimate effects on patterns of fruiting and fruit development in apples and grapes, p. 263-274. In: C.J. Wright (cd.). Manipulation of fruiting, 47th Nottingham Easter School. Butterworths, London.

Monteith, J.L. 1977. Climate and efficiency of crop production in Britain. Phil. Trans. R. Sot. London B. 281:277-294.

Palmer, J.W. 1976. Interception and utilization of light by apple orchards. PhD Diss., Univ. of Nottingham, U.K.

Palmer, J.W. 1981. Computed effects of spacing on light interception and distribution within hedgerow trees in relation to productivity. Acta Hort. 114:80-88.

Palmer, J.W. 1986. Light interception and dry matter production by apple orchards, p. 24-27. In: A. Lakso and F. Lenz (eds.) Regulation of photosynthesis in fruit trees. New York State Agr. Expt. Sta. Spec. Publ.
Palmer, J.W. 1987. The measurement of leaf area in apple trees. J. Hort. Sci. 62:5-10.

Palmer, J.W. 1988. Annual dry matter production and partitioning over the first 5 years of a bed system of Crispin/M.27 apple trees at four spacings. J. Applied Ecol. 25:569-578.

Palmer, J.W. 1989. Canopy manipulation for optimum utilization of light, p. 245-262. In: C.J. Wright (cd.). Manipulation of fruiting, 47th Nottingham Easter School. Butterworths, London.

Palmer, J.W. and J.E. Jackson. 1974. Effects of tree population and variations in spacing within and between rows of Golden Delicious on M.9. Rpt. E. Mailing Res. Sta. 1973:66-68.

Robinson, T. L., E.J. Seeley, and B.H. Barritt. 1983. Effect of light environment and spur age on 'Delicious' apple fruit size and quality. J. Amer. Soc. Hort. Sci. 108:855-861.

Robinson, T. L., A. N. Lakso, and S. G. Carpenter; 1991. Canopy development, yield, and fruit quality of 'Empire' and 'Delicious' apple trees grown in four orchard production systems for ten years. J. Amer. Soc. Hort. Sci. 116(2):179-187.

Wertheim, S. J., A. de Jager, and M.J.J.P. Duyzens. 1986. Comparison of single-row and multi-row planting systems with apple, with regard to productivity, fruit size and colour, and light conditions. Acta Hort. 160:243-258.

Westwood, M.N. and A.N. Roberts. 1970. The relationship between trunk cross-sectional area and weight of apple trees. J. Amer. Soc. Hort. Sci. 95:28-30. 